\title{
New trends in the foundations of science
}

\author{
Jean-Yves Béziau • Décio Krause
}

Published online: 15 December 2006

(C) Springer Science+Business Media B.V. 2006

In April 2002, during a trip to South America, Prof. Patrick Suppes spent 3 days in Florianópolis, the capital of the Santa Catarina State, Brazil. Ever since we hear about his trip (one of the organizers of this volume, JYB, was in Stanford some months before), we planed to invite Prof. Suppes for a meeting here to see his old friends, to know others, to know our university and activities, and also to celebrate his 80th birthday (Suppes was born in March 17, 1922). So, we organized a meeting called 'Two days with Patrick Suppes' and invited some people who had worked with him in Stanford, so as other people who know his work and are strongly influenced by his ideas. Furthermore, the simple presence of one of the leading present day philosophers of science in our group of research would motivate students and colleagues, and push further studies in an area we are trying to develop in Brazil, namely, the philosophical analysis of the foundations of science based on logical and mathematical recent developments, like non-classical logics and non-standard set theories.

Florianópolis is a small town in a beautiful island in the South of Brazil. Many years ago, people coming from the Azores settled down here after exterminating a bunch of "savages". A few centuries later, these people where themselves maltreated by people coming from Rio de Janeiro, leaded by Marshal Floriano, who, as a result of his victory, renamed the main city of the island, Florianópolis ("The City of Floriano"). More recently, another wave of 'immigrants' from several Brazilian States interested

Papers dedicated to the 80th birthday of Patrick Suppes presented in Florianópolis, Brazil, April 22-23, 2002.

J. Y. Béziau ( $\otimes)$

University of Neuchâtel, Institute of Logic,

Espace Louis Agassiz 1,

2000 Neuchâtel, Switzerland

e-mail: jean-yves.beziau@unine.ch

D. Krause

Department of Philosophy, Federal University of Santa Catarina,

Florianopolis, Brazil

e-mail: dkrause@cfh.ufsc.br 
in the foundations of science settled down nearby Florianópolis at the campus of the Federal University of Santa Catarina where, in 2000, a research group on the subject involving Brazilian researchers and others from abroad, was formally created at the Department of Philosophy by one of us (DK). In 2003, Professor Newton da Costa, one of the most distinguished researchers in this field, moved to Florianópolis and joined the group.

The link between these new settlers and Patrick Suppes started some years ago, from a time they were not yet in Florianópolis, through Rolando Chuaqui, a Chilean scientist and close friend of da Costa, who collaborated during many years with Suppes in Stanford. Subsequently, many people working with da Costa went to Stanford to meet Suppes: Francisco Antonio Doria, Adonai Sant'Ana, Acacio de Barros, and Jean-Yves Béziau spent some time there. Since all these people were at this time (2002) near to Florianópolis, and since Florianópolis was on the way of Patrick Suppes, who was going from Rio de Janeiro to Santiago of Chile, we decided to organize the meeting, gathering a few more people. The meeting was very pleasant, with animated discussions in a friendly atmosphere and nice dinners in some typical fish restaurants by the Lagoon. Although Patrick Suppes is a famous name in the present day philosophy of science (his work ranges from meteorology, his first scientific love, to the exploration of the brain, his last scientific passion, through logic, psychology, education, ethics, the foundations of physics, to name a few), unfortunately few people in Brazil know the importance of his work. Maybe this is due to the fact that the tradition of the philosophy departments of our universities is more concerned with the history of the philosophy of science than with philosophy of science properly, a task which presently requires background in logic, mathematics, and in the specific sciences. So, to join people from several Brazilian states and universities, who have had strong commitment with Suppes' way of doing philosophy was a nice opportunity to plan future activities and congregate people, so as to pursue the necessary technical background for really doing philosophy of science.

The meeting, held in the Department of Philosophy of the Federal University of Santa Catarina (UFSC), sponsored by the own university, reflected in some sense our present day variety of interests, by gathering people having worked in different aspects of the foundations of sciences, like physics, biology, logic, etc., but all of them with a strong commitment to logic and logical aspects of science. Suppes delivered a lecture, "Rationality and Freedom", and attended to all talks, so as discussed their subjects in accordance with his own way of seeing the topics. The resulting papers are those presented in this volume. These papers present original contributions by the authors. At first glace, they may seem to be not related one each other. But if we consider that all of them deal with foundational issues, and if we also pay attention to the way they are written, practically without speculation, but using formal tools, they can be seen as entirely inside Suppes' own methodology.

The contents can be summarized as follows: De Barros and Mendona deal with a subject (Bohmian Quantum Mechanics) to which they have made several original contributions, some of them in previous papers co-authored by Suppes himself. Béziau treats the notions of sentence and proposition, so as the relation between them, mainly from the point of view of the notion of identity that can be applied to them. Da Costa and Bueno discuss the link between the concept of quasi-truth, which generalize the usual Tarskian definition of truth, and paraconsistency. Doria's contribution goes towards the solution of the classical problem about the relationship between $\mathrm{P}$ and NP classes of computational problems. He dwells on the algorithmic implementation 
of a proof of Paris-Harrington theorem as proposed by Kunen. Krause and French introduce 'quantum sortal predicates' as a particular case of sortal predicates, which instead of providing a process of counting, give a 'criterion of cardinality'. Buchsbaum et al. enter in the discussion of the logical basis of scientific reasoning, moving to the indetermination of theories, while Sant'Anna and Guerrer discuss issues about the language of theoretical physics.

The goals of the meeting were fully achieved, and we hope that this volume will offers to the reader an idea of some of the lines of research which have been developed in Brazil, some of them in strong connection with Suppes' ideas. We would like to thank the Center of Philosophy and Human Sciences, the Department of Philosophy, and the PRPG/UFSC for the support, so as the following people who act as referees for the works here presented: Osvaldo Pessoa Jr., Dagffin Follesdal, Mark Colyvan, Carlos Lungarzo, Marcel Guillaume, Charbel Ñino El Hani, Gustavo Caponi, Vladimir Bazhanov, Shahid Rhamann, Gilberto Medeiros Kremer, Maurizzio Ruzzi, Carlos Ourivio Escobar, Darko Sarenac, Alexandre Costa Leite, and the referees of Synthese. 